\title{
Unionization Structure, Licensing and Innovation
}

\author{
Arijit Mukherjee* \\ Enrico Pennings***
}

*University of Nottingham, and The Leverhulme Centre for Research in Globalisation and Economic Policy, UK;

** Erasmus University Rotterdam, and Tinbergen Institute. 


\section{Tinbergen Institute}

The Tinbergen Institute is the institute for economic research of the Erasmus Universiteit Rotterdam, Universiteit van Amsterdam, and Vrije Universiteit Amsterdam.

Tinbergen Institute Amsterdam

Roetersstraat 31

1018 WB Amsterdam

The Netherlands

Tel.: $\quad+31(0) 205513500$

Fax: $\quad+31(0) 205513555$

Tinbergen Institute Rotterdam

Burg. Oudlaan 50

3062 PA Rotterdam

The Netherlands

Tel.: $\quad+31(0) 104088900$

Fax: $\quad+31(0) 104089031$

Please send questions and/or remarks of nonscientific nature to driessen@tinbergen.nl.

Most TI discussion papers can be downloaded at http://www.tinbergen.nl. 


\title{
Unionization Structure, Licensing and Innovation
}

\author{
Arijit Mukherjee \\ University of Nottingham and The Leverhulme Centre for Research in \\ Globalisation and Economic Policy, UK \\ and \\ Enrico Pennings \\ Erasmus University Rotterdam and Tinbergen Institute, The Netherlands
}

November 2005

\begin{abstract}
Taking technological differences between firms as given, we show that the technologically advanced firm has a stronger incentive for technology licensing under a decentralized unionization structure than with centralized wage setting. Furthermore, We show that, in presence of licensing, the incentive for innovation may also be stronger under decentralized unions. Unions have a clear preference for centralization only if productivity improvements are relatively small.
\end{abstract}

JEL Classification: D43, L13, O34

Key Words: Downstream market, Entry, Upstream market, Welfare

Correspondence to: Arijit Mukherjee, School of Economics, University of Nottingham, University Park, Nottingham, NG7 2RD, UK

E-mail: arijit.mukherjee@nottingham.ac.uk

Fax: +44-115-951 4159 


\section{Unionization Structure, Licensing and Innovation}

\section{Introduction}

It is commonly believed that a workforce with identical workers is better off being organized in a single union rather than in separate unions, which bargain independently with an employer. A single union eliminates competition between the individual unions and results in greater bargaining strength, which will be beneficial to workers (Horn and Wolinsky, 1988; Davidson, 1988). This belief gets support from the view that firms may establish multinational operations to increase their bargaining power with the individual workforces (Cowling, 1982, ch. 6) and with the evidence that divisionalization in the UK was, in part, a response to increasing union bargaining (Marginson, 1985). However, in an earlier work, Ulph (1989) shows that it is not always true that workers are better off with a single union than with separate unions. If the firm and workers cannot commit to a long-term contract, decentralized unions induce the firms to increase their investments, which is in the interest of the workers. So, even if separate unions create competition between unions, the benefit of higher investment by firms may outweigh this loss and make the workers better off.

This paper provides a new reason to support workers' preference for decentralized unions. We show that unionization structures may affect the decision on technology licensing, which is an important element of conduct in today's business world, ${ }^{1}$ and may have important implications on the welfare of workers. Particularly, we show that a technologically superior firm has a stronger incentive to license its technology to a technologically inferior firm when unions are separate compared to the situation with a single union. Technology licensing between firms increases

\footnotetext{
${ }^{1}$ Given the vast literature on technology licensing, we do not try to review that literature here. Instead, we refer to Rostoker (1984) and Kamien (1992) for surveys on technology licensing.
} 
outputs and, hence, demand for workers. We find that, if technology licensing occurs irrespective of the unionization structure, workers are better off under a centralized unionization structure. But, if technology licensing occurs only under separate unions, workers may be better off under a decentralized unionization structure.

We further show that technology licensing is a profitable strategy for all feasible technological differences between the firms under decentralized unions. It is found that even if the technologically efficient firm is a monopolist in the economy, it has the incentive to create competition by licensing its technology to a competitor. The finding is in line with Naylor (2002) who shows that, with endogenous input prices, a monopolist has the incentive to license its technology even if the firms produce homogeneous products. ${ }^{2}$ However, with a centralized union, licensing is not a profitable strategy for a relatively large productivity differences between the firms. In this case, licensing would increase the wage rate substantially in the technologically advanced firm, thus making licensing unprofitable for large productivity differences. Under centralized unionization, licensing is profitable only for relatively small technological differences, and the technologically advanced firm will not be a monopolist for such a small technological advantage. Hence, for large productivity difference, licensing by a monopolist is profitable only under decentralized unions.

Building upon the result of stronger licensing incentives under decentralization, we show that innovation incentives are strongest under decentralization for a wide range of process innovations. Thus, our paper modifies the result by Haucap and Wey (2004), who show that the incentives for innovation are

\footnotetext{
${ }^{2}$ With exogenous input prices, it follows from Mukherjee and Balasubramanian (2001) and Faulí-Oller and Sandonis (2002) show that a monopolist final goods producer may have the incentive to license its technology to a competitor when the products are horizontally differentiated. In a two-country model with endogenous tariffs, Mukherjee and Pennings (2005) show that a monopolist producer of a final good has the incentive to license its technology even if the firms produce homogeneous products. Shepard (1987), Farrell and Gallini (1988) and Mukherjee and Ray (2005) also examine licensing by a monopolist input supplier.
} 
always strongest under centralized bargaining. Their result was a bit surprising ${ }^{3}$ as conventional beliefs (Horn and Wolinksy 1988 and Davidson, 1988) suggest that firms have a preference for decentralized negotiations due to the lower bargaining strength of workers when unions are separated. As union strength increases, unions extract a higher share of the rents from innovation, causing an adverse impact on the firm's return from R\&D investments. ${ }^{4}$ Finally, our analysis shows that unions have a clear preference for centralized bargaining only when productivity improvements are relatively small.

The remainder of the paper is organized as follows. Section 2 shows the effects of different unionization structure on technology licensing. In section 3 , we endogenize the firm's innovation decision. Section 4 concludes.

\section{Unionization structure and licensing}

Consider an economy with two firms, called 1 and 2 . These firms produce a homogeneous product and behave in the product market as Cournot duopolists. We assume that each firm needs two critical inputs for their production. These inputs are labor and an intermediate product. The wage rates for the workers are determined by the labor unions. For simplicity, we normalize the reservation wage of the workers to zero. We further assume that the market for the intermediate product is perfectly competitive and the price of each unit of the intermediate product is $c$.

\footnotetext{
${ }^{3}$ The result also seems at odds with the empirical literature on unionization where normally is found that stronger unions lead to lower innovation incentives (e.g., Conolly et al., 1986 and Acs and Audretch, 1988). Moreover, their result is in conflict with the trend over the past decades towards more decentralization (OECD, 2004), increased innovation and patenting, and more licensing of innovations (OECD, 2003).

${ }^{4}$ In a different setting with labor-saving innovation, Calabuig and Gonzalez-Maestre (2002) show the effect of market size on the incentive for innovation. For other papers on innovation in unionized labor market one may refer to Tauman and Weiss (1987) and Ulph and Ulph (1998).
} 
We refer to the unions attached to firms 1 and 2 as union 1 and union 2 respectively. Unions choose wage rates as to maximize their rents and firms hire workers according to their needs. Hence, we assume that the firms have right-tomanage autonomy over employment (see, e.g., Bughin and Vannini, 1995, Vannini and Bughin, 2000 and López and Naylor, 2004). ${ }^{5}$ In our analysis, we will consider two types of wage setting behavior of the unions: (i) decentralization, where the unions choose wage rates in order to maximize their own rents and (ii) centralization, where the unions form a single industry-wide union and set a uniform wage rate to maximize their joint rents. ${ }^{6}$

We consider the following production function of the firms. As to derive our main results in the simplest way, we assume that each firm needs just one worker to produce one unit of output. But, while firm 1 needs one unit of the intermediate product to produce one unit of output, firm 2 needs $\lambda>1$ units of the intermediate product to produce one unit of output. Hence, the production technology of firm 1 is superior to that of firm 2. Furthermore, assume that the inverse market demand function for the final goods is

$$
P=a-q,
$$

where the notations have usual meanings and $a>c$ for a meaningful analysis.

The game is played as follows. At stage 1, firm 1 decides whether to license its technology to firm 2 or not. In case of licensing, firm 1 gives a take-it-or-leave-it offer to firm 2 and charges an up-front fixed fee for its technology. ${ }^{7}$ At stage 2 , the unions

\footnotetext{
${ }^{5}$ This structure of labor union and firm is also similar to the earlier works of Dunlop (1944) and Oswald (1982).

${ }^{6}$ The intermediate case of 'coordination' where one industry union sets two possibly different wages for both firms is disregarded as to focus on the two polar cases of unionization structures.

${ }^{7}$ Royalty licensing severely complicates the analysis as they affect the marginal cost of the licensee, while the amount of the fixed fee has no impact on the strategic choices in the product market. Restricting the analysis to fixed fee isolates the strategic effects of technology transfer in the wage bargaining game from the strategic effects of licensing in the product market. As shown previously,
} 
set wage rates for the respective firms. At stage 3, the firms compete in the product market as Cournot duopolists. We solve the game through backward induction.

\subsection{Decentralized unions}

\subsubsection{No licensing}

Let us first consider the model without licensing. Given the wage rates $w_{1}$ and $w_{2}$, set by unions 1 and 2, respectively, equilibrium outputs of firms 1 and 2 in the product market are, respectively ${ }^{8}$

$$
\left\{\hat{q}_{1}, \hat{q}_{2}\right\}=\left\{\frac{a-2 w_{1}-2 c+w_{2}+\lambda c}{3}, \frac{a-2 w_{2}-2 \lambda c+w_{1}+c}{3}\right\}
$$

Given 'right-to-manage' where unions aim to maximize their wage bills ${ }^{9}$, reaction functions for the equilibrium wages are derived by maximizing $w_{1} \hat{q}_{1}$ and $w_{2} \hat{q}_{2}$ with respect to $w_{1}$ and $w_{2}$, respectively. Equilibrium wages are

$$
\left\{\hat{w}_{1}, \hat{w}_{2}\right\}=\left\{\frac{5 a-7 c+2 \lambda c}{15}, \frac{5 a-7 \lambda c+2 c}{15}\right\} .
$$

Substituting (3) in (2) gives the equilibrium outputs of firms 1 and 2 as

$$
\left\{\hat{q}_{1}, \hat{q}_{2}\right\}=\left\{\frac{2(5 a+2 \lambda c-7 c)}{45}, \frac{2(5 a-7 \lambda c+2 c)}{45}\right\}
$$

Equations (3) and (4) show that the equilibrium wage of union 2 and the equilibrium output of firm 2 are positive if and only if

$$
\lambda<\frac{5 a+2 c}{7 c}
$$

fixed fee licensing is optimal when the licensee can easily imitate the licensed technology or it is not possible to verify the outputs of the licensee, which is necessary for the provision of output royalty (Katz and Shapiro, 1985 and Rockett, 1990).

${ }^{8}$ In the different subsections the index for the unionization structure and the licensing decision is suppressed for the quantities and the wages.

9 A more general function of union's utility would be $q w^{m}$ where $m$ is a parameter $(0<m \leq 1)$ which captures the extent to which the union cares about employment vis-a-vis the wage rate. However, this complication will not add anything to the main purpose of this paper. 
We assume that this condition holds throughout the paper. Then, equilibrium profits of firms 1 and 2 are respectively

$$
\left\{\hat{\pi}_{1, d, n l}, \hat{\pi}_{2, d, n l}\right\}=\left\{\frac{4(5 a+2 \lambda c-7 c)^{2}}{2025}, \frac{4(5 a-7 \lambda c+2 c)^{2}}{2025}\right\} .
$$

Welfare, which is the sum of consumer surplus, wages and profits, is given by

$$
W_{d, n l}=\frac{2}{81}(2 a-\lambda c-c)^{2}+\frac{2}{405}(5 a+2 \lambda c-7 c)^{2}+\frac{2}{405}(5 a-7 \lambda c+2 c)^{2} .
$$

\subsubsection{Licensing}

Let us now consider licensing at stage 1. In case of licensing, both firms use the superior technology and need one unit of the intermediate product to produce one unit of output. Since firm 1 licenses against an up-front fixed-fee, the licensing fee does not affect the equilibrium outputs of the firms. Therefore, equilibrium outputs of firms 1 and 2 are respectively

$$
\left\{\hat{q}_{1}, \hat{q}_{2}\right\}=\left\{\frac{a-2 w_{1}-c+w_{2}}{3}, \frac{a-2 w_{2}-c+w_{1}}{3}\right\} .
$$

Unions 1 and 2 maximize the respective wage bills, $w_{1} \hat{q}_{1}$ and $w_{2} \hat{q}_{2}$, with respect to $w_{1}$ and $w_{2}$, respectively. The intersection of the resulting reaction functions provide us with the equilibrium wages:

$$
\left\{\hat{w}_{1}, \hat{w}_{2}\right\}=\left\{\frac{a-c}{3}, \frac{a-c}{3}\right\} .
$$

Substituting the equilibrium wages into the equilibrium outputs, we find that

$$
\left\{\hat{q}_{1}, \hat{q}_{2}\right\}=\left\{\frac{2(a-c)}{9}, \frac{2(a-c)}{9}\right\} \text {. }
$$

The equilibrium profits of firms 1 and 2 are, respectively 


$$
\left\{\hat{\pi}_{1, d, l}, \hat{\pi}_{2, d, l}\right\}=\left\{\frac{4(a-c)^{2}}{81}+F, \frac{4(a-c)^{2}}{81}-F\right\},
$$

where $F$ is the up-front fixed-fee charged by firm 1 . Since, firm 1 gives a take-it-orleave-it offer to firm 2, the optimal value of the fixed-fee is

$$
F=\frac{4(a-c)^{2}}{81}-\frac{4(5 a-7 \lambda c+2 c)^{2}}{2025}
$$

Hence, net profits of firms 1 and 2 under licensing are respectively

$$
\left\{\hat{\pi}_{1, d, l}, \hat{\pi}_{2, d, l}\right\}=\left\{\frac{8(a-c)^{2}}{81}-\frac{4(5 a-7 \lambda c+2 c)^{2}}{2025}, \frac{4(5 a-7 \lambda c+2 c)^{2}}{2025}\right\} .
$$

Finally, welfare can be calculated as

$$
W_{d, l}=\frac{28}{81}(a-c)^{2} \text {. }
$$

Proposition 1: Under decentralized unions, licensing is profitable for any feasible $\lambda$. Proof: Comparing profit of firm 1 under licensing in equation (13) with its profit without licensing in equation (6), we have $\hat{\pi}_{1, d, l}-\hat{\pi}_{1, d, n l}=$ $\frac{1}{2025}\left\{a c(-200+200 \lambda)+c^{2}\left(-12+224 \lambda-212 \lambda^{2}\right)\right\}$. So, $\hat{\pi}_{1, d, l}-\hat{\pi}_{1, d, n l}>0$ if and only if $a(-50+50 \lambda)+c\left(-3+56 \lambda-53 \lambda^{2}\right)>0$. Solving the quadratic equation yields $\hat{\pi}_{1, d, l}-\hat{\pi}_{1, d, n l}>0 \quad$ for $\quad 1<\lambda<\frac{50 a+3 c}{53 c}$, which always holds since $1<\lambda<\frac{5 a+2 c}{7 c}<\frac{50 a+3 c}{53 c}$.

The above proposition shows that, if there are separate unions, licensing always occurs, even for a value of $\lambda$ that makes the technologically advanced firm monopolist. Therefore, the union rent under decentralization is 


$$
u_{d, l}=\frac{4(a-c)^{2}}{27}
$$

Proposition 2: Under decentralized unions, licensing is welfare improving for any feasible $\lambda$.

Proof: Comparing welfare under licensing in equation (14) with welfare without $\begin{array}{lllll}\text { licensing in } & \text { equation } & \text { we }\end{array}$ $W_{d, l}-W_{d, n l}=\frac{a c}{405}(-140+140 \lambda)+\frac{c^{2}}{405}\left(24+92 \lambda-116 \lambda^{2}\right)$. Hence, $W_{d, l}>W_{d, n l}$ if and only if $29 \lambda^{2} c-23 \lambda c-35 \lambda a+35 a-6 c<0$. Solving this inequality yields $W_{d, l}>W_{d, n l}$ for $1<\lambda<\frac{70 a-12 c}{58 c}$. Since $1<\lambda<\frac{5 a+2 c}{7 c}<\frac{70 a-12 c}{58 c}$, licensing is welfare improving for any feasible $\lambda$.

\subsection{Centralized union}

\subsubsection{No licensing}

Though firm-specific bargaining is a valid assumption for countries like the U.S. and Canada, unions often operate in a centralized framework in other countries (e.g., the Scandinavian countries). When bargaining is centralized, the sum of the total wage bill, $w\left(q_{1}+q_{2}\right)$, is maximized with respect to a uniform wage for both firms. ${ }^{10}$ Since total output of the firms is $\frac{1}{3}(2 a-2 w-c-\lambda c)$, the equilibrium wage can be calculated as

$$
\hat{w}=\frac{1}{2} a-\frac{1}{4} c(1+\lambda)
$$

Hence, the equilibrium outputs are

\footnotetext{
${ }^{10}$ The labor union in the UK universities may be an example for this situation. It bargains as a national body for the same wage rate in all the UK universities irrespective of their productivity differences.
} 


$$
\left\{\hat{q}_{1}, \hat{q}_{2}\right\}=\left\{\frac{2 a-7 c+5 \lambda c}{12}, \frac{2 a-7 \lambda c+5 c}{12}\right\}
$$

Note that both firms produce in the market for $\lambda<\frac{2 a+5 c}{7 c}$. Since this is a stronger condition on $\lambda$ than the condition required to maintain the duopoly structure under decentralized unionization, monopoly is more likely with centralized wage setting.

The equilibrium profits of the firms are

$$
\left\{\hat{\pi}_{1, c, n l}, \hat{\pi}_{2, c, n l}\right\}=\left\{\left(\frac{2 a-7 c+5 \lambda c}{12}\right)^{2},\left(\frac{2 a-7 \lambda c+5 c}{12}\right)^{2}\right\} .
$$

Welfare is given by

$$
W_{c, n l}=2\left(\frac{2 a-c-\lambda c}{6}\right)^{2}+\left(\frac{2 a-7 c+5 \lambda c}{12}\right)^{2}+\left(\frac{2 a-7 \lambda c+5 c}{12}\right)^{2} .
$$

\subsubsection{Licensing}

When firm 1 licenses its technology to firm 2, the equilibrium wage under a centralized unionization structure is

$$
\hat{w}=\frac{1}{2}(a-c) .
$$

The equilibrium outputs are

$$
\left\{\hat{q}_{1}, \hat{q}_{2}\right\}=\left\{\frac{1}{6}(a-c), \frac{1}{6}(a-c)\right\},
$$

and the equilibrium profit of firms 1 and 2 are

$$
\left\{\hat{\pi}_{1, c, l}, \hat{\pi}_{2, c, l}\right\}=\left\{\frac{1}{36}(a-c)^{2}+F, \frac{1}{36}(a-c)^{2}-F\right\} .
$$

Since the fixed fee that firm 1 will charge will make firm 2 indifferent between accepting the licensing contract and not, the optimal amount of fixed fee will be

$$
\hat{F}=\frac{1}{36}(a-c)^{2}-\left(\frac{2 a-7 \lambda c+5 c}{12}\right)^{2} .
$$


Substituting the optimal fixed fee in (22) yields

$$
\left\{\hat{\pi}_{1, c, l}, \hat{\pi}_{2, c, l}\right\}=\left\{\frac{1}{18}(a-c)^{2}-\left(\frac{2 a-7 \lambda c+5 c}{12}\right)^{2},\left(\frac{2 a-7 \lambda c+5 c}{12}\right)^{2}\right\} .
$$

Welfare is equal to

$$
W_{c, l}=\frac{5}{18}(a-c)^{2}
$$

Proposition 3: Under centralized unionization, licensing is profitable for $1<\lambda<\lambda^{l}=\frac{4 a+33 c}{37 c}$

Proof: Comparing $\hat{\pi}_{1, c, l}$ with $\hat{\pi}_{1, c, n l}$, we find that $\hat{\pi}_{1, c, l}>\hat{\pi}_{1, c, n l}$ if and only if $\frac{1}{18}(a-c)^{2}>\frac{1}{144}(2 a-7 \lambda c+5 c)^{2}+\frac{1}{144}(2 a-7 c+5 \lambda c)^{2}$. The condition can be rewritten as

$$
\frac{1}{18} c^{2}-\frac{1}{9} a c>\frac{1}{144} c^{2}\left(74 \lambda^{2}-140 \lambda+74\right)-\frac{1}{18} a c(\lambda+1)
$$
$c\left(37 \lambda^{2}-70 \lambda+33\right)-4 a(\lambda-1)<0$. It can be shown from this inequality that $\hat{\pi}_{1, c, l}>\hat{\pi}_{1, c, n l}$ for $1<\lambda<\frac{4 a+33 c}{37 c}$.

The above proposition shows that firm 1 has no incentive to license for the productivity advantage that makes it monopolist (i.e. for $\lambda \geq \frac{2 a+5 c}{7 c}$ ). So, the monopolist has the incentive to create competition through licensing only if the unions are decentralized.

We find that the union rent is

$$
u_{c, l}=\frac{(a-c)^{2}}{6}
$$


for $1<\lambda<\lambda^{l}$. However, licensing does not occur for $\lambda>\lambda^{l}$. For this parameter range, the union rent equals

$$
u_{c, n l}=\frac{(2 a-c-c \lambda)^{2}}{24}
$$

Proposition 4: Under centralized unionization, licensing is welfare improving for $1<\lambda<\frac{20 a+21 c}{41 c}$

Proof: We get

$$
W_{c, l}-W_{c, n l}=\frac{a c}{144}(-40+40 \lambda)+\frac{c^{2}}{144}\left(-42+124 \lambda-82 \lambda^{2}\right)
$$

Hence, $W_{c, l}>W_{c, n l}$ if and only if $41 \lambda^{2} c-62 \lambda c-20 \lambda a+20 a+21 c<0$. Solving the inequality yields $W_{c, l}>W_{c, n l}$ for $1<\lambda<\frac{20 a+21 c}{41 c}$.

Thus, unlike decentralized unions, which matched private and social incentives for licensing, the centralized union provides a range of $\lambda$ for which the licensing decisions of a firm and a social planner diverge.

\subsection{A comparison of the union structures}

Now, we are in a position to see whether workers are better off under separate (decentralized) unions or a single (centralized) union.

Proposition 5: (i) If there is licensing under both decentralized and centralized unionization structures, workers are better off under centralized union. 
(ii) If licensing occurs only under decentralized union, workers may be better off under decentralized union.

Proof: (i) Comparing $u_{d, l}$ and $u_{c, l}$ for $1<\lambda<\lambda^{l}$, we find that the former is always lower than the latter.

(ii) If $\lambda>\lambda^{l}$, licensing occurs only under decentralized unions. From equations (15) and (27), we find that $u_{d, l} \stackrel{>}{<} u_{c, n l}$ if and only if $\frac{4(a-c)^{2}}{27} \stackrel{>}{<}=\frac{(2 a-c-c \lambda)^{2}}{24}$. Hence, there is $\lambda=\frac{(6-4 \sqrt{2}) a-(3-4 \sqrt{2}) c}{3 c}$ in the interval $\left[\lambda^{l}, \frac{2 a+5 c}{7 c}\right]$ at which the union rent in (15) equals the union rent in (27). Since the union rent in (27) decreases with $\lambda$, the union rent under decentralized unions is higher than that of under centralized union for $\lambda \in\left(\frac{(6-4 \sqrt{2}) a-(3-4 \sqrt{2}) c}{3 c}, \frac{2 a+5 c}{7 c}\right)$.

\section{Innovation Incentives}

The previous section has considered the effect of licensing in an asymmetric duopoly that may arise due to innovation by firm 1 . In this section, we endogenize the innovation decision and examine how licensing and unionization structure affect the incentive for innovation. We show that our results may be in contrast to the recent work by Haucap and Wey (2004), who derive that the incentives for innovation are always higher under centralized unionization structure. However, unlike the present paper, they have ignored technology licensing, which is an increasingly popular strategy for firms to raise revenues.

We consider a game similar to previous section with the exception that now there is another stage before technology licensing where firm 1 decides whether to 
innovate or not. So, at stage 1 , firm 1 decides whether to innovate that reduces its intermediate input requirement from $\lambda$ to 1 . At stage 2 , firm 1 decides whether to license its technology to firm 2, conditional on its decision on innovation. If there is no innovation at stage 1 , there is no licensing at stage 2 , since both firms use the technology that requires $\lambda$ units of intermediate inputs to produce 1 unit of output. At stage 3 , the union sets the wage rate for the firms according to its unionization structure. At stage 4, productions take place and the profits are realized. As usual, we solve the game through backward induction.

Let us first consider the situation where firm 1 does not innovate at stage 1 , and therefore, both firms need $\lambda$ units of the intermediate product to produce one unit of output. In this situation, profit of each firm equals $\frac{1}{36}(a-\lambda c)^{2}$ and $\frac{4}{81}(a-\lambda c)^{2}$ under centralized and decentralized unions, respectively.

If firm 1 innovates at stage 1 , the market outcomes will follow from our analysis of the previous section. Using those results, we derive the following proposition.

Proposition 6: There exist two thresholds, $\lambda^{*}=\frac{60 a+967 c}{1027 c}$ and $\lambda * *=\frac{1380 a+8081 c}{9461 c}$, with $1<\lambda^{*}<\lambda^{l}<\lambda * *$, such that the benefits from innovation are higher under a decentralized unionization structure for $\lambda^{*}<\lambda<\lambda * *$ and under a centralized unionization structure otherwise.

Proof: It follows from Propositions 1 and 3 that licensing always occurs under decentralized union, but it occurs under centralized union only for $\lambda<\lambda^{l}=\frac{4 a+33 c}{37 c}$. 
Firm 1 does innovation if innovation increases its profit as compared to no innovation. If the union is decentralized, firm 1's maximal benefit from innovation is

$$
R^{d, l}=\frac{8(a-c)^{2}}{81}-\frac{4(5 a-7 \lambda c+2 c)^{2}}{2025}-\frac{4(a-\lambda c)^{2}}{81}
$$

Firm 1's maximal benefit from innovation under centralized union is

$$
\begin{array}{lll}
R^{c, l}=\frac{(a-c)^{2}}{18}-\left(\frac{2 a-7 \lambda c+5 c}{12}\right)^{2}-\frac{(a-\lambda c)^{2}}{36} & \text { for } & \lambda<\lambda^{l} \\
R^{c, n l}=\left(\frac{2 a-7 c+5 \lambda c}{12}\right)^{2}-\frac{4(a-\lambda c)^{2}}{81} & \text { for } \quad \lambda>\lambda^{l} .
\end{array}
$$

Comparing (28) with (29), we find that the benefit from innovation is higher under centralized union for $\lambda<\lambda^{*}=\frac{60 a+967 c}{1027 c}$, where $1<\lambda^{*}<\lambda^{l}$. It follows from (28) and (30) that the benefit from innovation is higher under centralized union for $\lambda>\lambda * *=\frac{1380 a+8081 c}{9461 c}$, where $\frac{2 a+5 c}{7 c}>\lambda * *>\lambda^{l}$ (and $\frac{2 a+5 c}{7 c}$ is the value of $\lambda$ that ensures duopoly under centralized union with innovation).

Therefore, the benefit from innovation is higher under decentralized union for $\lambda^{*}<\lambda<\lambda * *$ and under centralized union otherwise.

The above proposition has assumed away the cost of innovation and has shown that the benefits from innovation are higher under decentralized union for $\lambda^{*}<\lambda<\lambda^{* *}$. Hence, it is easy to understand that there are costs of innovation such that innovation will occur only under decentralized union for $\lambda^{*}<\lambda<\lambda * *$.

We find that innovation incentives are stronger under centralized union provided the productivity improvement is sufficiently small or sufficiently large, even exceeding the threshold above which the firm, according to Proposition 3, will not 
license the new technology. For a wide intermediate range of productivity improvements attributable to innovation, the incentives for innovation are higher under decentralized union. The difference between our result and Haucap and Wey (2004) is caused by the profitability of licensing. As shown in the previous section, licensing incentives are much stronger under decentralized union. For intermediate productivity improvements, the profit differential from licensing under decentralized and centralized unions is large enough to counter the strongest innovation incentives under centralized union without licensing found in Haucap and Wey (2004).

As a final remark, it is worth mentioning that our analysis can easily be extended to model the decision on unionization structure. For a relatively small productivity improvement, i.e., for $\lambda<\lambda^{*}$, the result is clear. Centralized unionization is preferable since it is not only best for workers given a technological advantage over the other firm (Proposition 5), but also spurs innovation that leads to such a technological advantage (Proposition 6). For higher levels of productivity improvements, there is a trade-off between innovation incentives and licensing incentives. For example, for a sufficiently high level of productivity improvement, the incentive to innovate is higher under centralization, but such a unionization structure hinders licensing. If the cost of innovation is sufficiently low such that innovation would occur regardless of the unionization structure, Proposition 5 advocates a decentralized structure for the unions.

\section{Conclusion}

It is usually believed that workers are better off in a centralized union. However, this view ignores the strategic non-production activities of the firms. In a simple model with technology licensing, we show that workers may be better off under 
decentralized unions, since the incentive for technology licensing is decreasing in the degree of centralization. In contrast to the existing literature, our result also shows that a monopolist firm may have the incentive for creating competition through technology licensing when the labor market is unionized. However, this occurs only if the labor union is decentralized.

While endogenizing the incentive for innovation, we show that the incentive for innovation is higher under decentralized union for moderate productivity improvement from innovation. But, the incentive for innovation is higher under centralized union if the productivity improvement from innovation is either very small or very large. Finally, our analysis indicates that unions will unambiguously prefer a centralized structure if the productivity improvement from innovation is very small. For relatively higher productivity improvement from innovation, there is ambiguity about the workers preference for centralized or decentralized unions, and the choice depends on the relative benefit of technology licensing and innovation. 


\section{References}

Acs, Z. and D. Audretsch, 1988, 'Innovation in large and small firms: an empirical analysis', American Economic Review, 78: 678 - 90.

Bughin, J and S. Vannini, 1995, 'Strategic direct investment under unionized oligopoly', International Journal of Industrial Organization, 13: 127 - 45.

Calabuig, V. and M. Gonzalez-Maestre, 2002, 'Union structure and incentives for innovation', European Journal of Political Economy, 18, 177 - 92.

Conolly, R., B. Hirsch and M. Hirschey, 1986, 'Union rent seeking, intangible capital and market value of the firm, Review of Economics and Statistics, 68, 567 77.

Cowling, K., 1982, Monopoly capitalism, London, Macmillan.

Davidson, C., 1988, 'Multiunit Bargaining in oligopolistic industries', Journal of Labor Economics 6, 397 - 422.

Dunlop, J. T., 1944, Wage determination under trade union, New York, Macmillan. Farrell, J. and N. Gallini, 1988, 'Second-sourcing as commitment: monopoly incentives to attract competition', The Quarterly Journal of Economics, 103: 673 94.

Faulí-Oller, R. and J. Sandonis, 2002, 'Welfare reducing licensing', Games and Economic Behavior, 41: 192 - 205.

Haucap, J. and C. Wey, 2004, 'Unionisation structures and innovation incentives', Economic Journal 114: C149 - 65.

Horn, H. and A. Wolinsky, 1988, 'Bilateral monopolies and incentive for merger', Rand Journal of Economics 19, 408 - 19.

Kamien, M., 1992, 'Patent licensing', in R. J. Aumann and S. Hart (Eds.), Handbook of game theory, ch. 11, Elsevier. 
Katz, M. L. and C. Shapiro, 1985, 'On the licensing of innovations', RAND Journal of Economics, 16: $504-20$.

López, M. C. and R. A. Naylor, 2004, 'The Cournot-Bertrand profit differential: a reversal result in a differentiated duopoly with wage bargaining', European Economic Review, 48: 681 - 96.

Marginson, P., 1985, 'The multidivisional firm and control over the work process', International journal of Industrial Organization, 3: 37 - 56.

Mukherjee, A. and A. Ray, 2005, 'Strategic outsourcing and R\&D in a vertical structure', Mimeo, School of Economics, University of Nottingham.

Mukherjee, A. and N. Balasubramanian, 2001, 'Technology transfer in horizontally differentiated product-market', Research in Economics (Richerche Economiche), 55: $257-74$.

Mukherjee, A. and E. Pennings, 2005, 'Tariffs, licensing and market structure', European Economic Review (forthcoming).

Naylor, R., 2002, 'Industry profits and competition under bilateral oligopoly', Economics Letters, 77: $169-75$.

OECD, 2003, Turning science into business, Paris.

OECD, 2004, Employment outlook, Paris.

Oswald, A. J., 1982, 'The microeconomic theory of the trade union', Economic Journal, 92: $269-83$.

Rockett, K., 1990, 'The quality of licensed technology', International Journal of Industrial Organization, 8: 559 - 74.

Rostoker, M., 1984, 'A survey of corporate licensing', IDEA, 24: 59 - 92.

Shepard, A., 1987, 'Licensing to enhance the demand for a new product', RAND Journal of Economics, 18: 360 - 68 . 
Tauman, Y. and Y. Weiss, 1987, 'Labor unions and the adoption of new technology', Journal of Labor Economics, 5: 477 - 501.

Ulph, A., 1989, 'The incentives to make commitments in wage bargains', Review of Economic Studies, 56: 449 - 66.

Ulph, A. and D. Ulph, 1998, 'Labour markets, bargaining and innovation', European Economic Review, 42: 931 - 39.

Vannini, S. and J. Bughin, 2000, 'To be (unionized) or not to be? a case for costraising strategies under Cournot oligopoly', European Economic Review, 44: 1763 81. 